\title{
Effects of Oxygen Plasma Treatments on Surface Functional Groups and Shear Strength of Carbon Fiber Composites
}

\section{Supporting information}

\author{
Zhongyao Zhang ${ }^{1}$, Jennifer L. Wilson ${ }^{2}$, Brian R. Kitt ${ }^{2}$ and David W. Flaherty ${ }^{1 *}$ \\ ${ }^{1}$ Department of Chemical and Biomolecular Engineering, University of Illinois at \\ Urbana-Champaign, Urbana, IL 61801, United States \\ ${ }^{2}$ Spirit AeroSystems, Inc. Wichita, KS 67210, United States
}

\author{
*Corresponding Author \\ Phone: (217) 244-2816 \\ Email: dwflhrty@illinois.edu
}




\section{S1 Raw Data from Lap Shear Tests of All Coupons Examined}

We performed plasma treatments on T300 laminates with varied plasma treatment power $(0-300 \mathrm{~W})$ or time $(0-8$ $\mathrm{min})$, and oxygen flow rate is $25 \mathrm{~cm}^{3} \mathrm{~min}^{-1}$ under low pressure $(30 \pm 3 \mathrm{~Pa})$. Shear strengths here are used to perform one-way analysis of variance between raw coupons and plasma treated ones. For simplification, we name the coupons treated under different conditions by plasma treatment power and time (e.g., $300 \mathrm{~W} 8 \mathrm{~min}$ ).

Table S1. Raw data of shear strength for all coupons tested by lap shear test

\begin{tabular}{|c|c|c|c|c|c|}
\hline & $\begin{array}{l}\text { Shear } \\
\text { strength } \\
(\mathrm{MPa})\end{array}$ & $\begin{array}{c}\text { Max } \\
\text { displacement } \\
(\mathrm{mm})\end{array}$ & $\begin{array}{l}\text { Gage } \\
\text { length } \\
(\mathrm{mm})\end{array}$ & $\begin{array}{l}\text { Width } \\
(\mathrm{mm})\end{array}$ & $\begin{array}{l}\text { Max load } \\
\text { (kg) }\end{array}$ \\
\hline \multirow{30}{*}{$\begin{array}{l}\text { Raw } \\
\text { coupons }\end{array}$} & 25.97 & 0.16 & 6.21 & 12.64 & 207.84 \\
\hline & 25.93 & 0.15 & 6.26 & 12.66 & 209.60 \\
\hline & 19.48 & 0.11 & 6.27 & 12.64 & 157.49 \\
\hline & 25.83 & 0.15 & 6.32 & 12.65 & 210.69 \\
\hline & 25.49 & 0.16 & 6.29 & 12.66 & 206.88 \\
\hline & 21.44 & 0.12 & 6.29 & 12.62 & 173.45 \\
\hline & 20.32 & 0.11 & 6.20 & 12.65 & 162.43 \\
\hline & 26.49 & 0.15 & 6.21 & 12.65 & 212.19 \\
\hline & 16.25 & 0.10 & 6.39 & 12.65 & 133.95 \\
\hline & 26.04 & 0.15 & 6.26 & 12.67 & 210.74 \\
\hline & 26.87 & 0.16 & 6.17 & 12.66 & 214.14 \\
\hline & 24.64 & 0.16 & 6.29 & 12.65 & 199.81 \\
\hline & 25.21 & 0.15 & 6.26 & 12.65 & 203.62 \\
\hline & 25.34 & 0.15 & 6.25 & 12.65 & 204.25 \\
\hline & 18.13 & 0.11 & 6.26 & 12.64 & 146.28 \\
\hline & 25.02 & 0.14 & 6.36 & 12.66 & 205.57 \\
\hline & 18.15 & 0.11 & 6.30 & 12.65 & 147.51 \\
\hline & 25.92 & 0.16 & 6.31 & 12.66 & 211.24 \\
\hline & 26.05 & 0.16 & 6.29 & 12.67 & 211.65 \\
\hline & 22.07 & 0.13 & 6.26 & 12.67 & 178.58 \\
\hline & 26.28 & 0.16 & 6.25 & 12.67 & 212.24 \\
\hline & 26.60 & 0.17 & 6.31 & 12.67 & 217.04 \\
\hline & 26.35 & 0.16 & 6.35 & 12.67 & 216.27 \\
\hline & 19.65 & 0.12 & 6.30 & 12.66 & 159.80 \\
\hline & 26.63 & 0.17 & 6.25 & 12.67 & 215.09 \\
\hline & 10.15 & 0.05 & 6.22 & 12.43 & 80.06 \\
\hline & 26.32 & 0.15 & 6.24 & 12.67 & 212.10 \\
\hline & 25.29 & 0.15 & 6.27 & 12.69 & 205.30 \\
\hline & 26.66 & 0.16 & 6.27 & 12.66 & 215.96 \\
\hline & 26.61 & 0.15 & 6.25 & 12.66 & 214.73 \\
\hline \multirow{9}{*}{$\begin{array}{l}100 \mathrm{~W} \\
8 \mathrm{~min}\end{array}$} & 26.13 & 0.15 & 6.24 & 12.73 & 211.42 \\
\hline & 28.35 & 0.16 & 6.24 & 12.73 & 229.38 \\
\hline & 20.43 & 0.13 & 6.26 & 12.75 & 166.29 \\
\hline & 22.04 & 0.12 & 6.20 & 12.73 & 177.26 \\
\hline & 17.72 & 0.10 & 6.30 & 12.73 & 144.83 \\
\hline & 26.74 & 0.16 & 6.20 & 12.73 & 215.05 \\
\hline & 28.40 & 0.17 & 6.17 & 12.73 & 227.48 \\
\hline & 27.25 & 0.16 & 6.24 & 12.71 & 220.26 \\
\hline & 18.64 & 0.11 & 6.24 & 12.75 & 151.14 \\
\hline
\end{tabular}




\begin{tabular}{|c|c|c|c|c|c|}
\hline & 27.04 & 0.16 & 6.22 & 12.73 & 218.31 \\
\hline & 27.32 & 0.16 & 6.18 & 12.73 & 219.27 \\
\hline & 27.62 & 0.17 & 6.25 & 12.73 & 223.94 \\
\hline & 27.28 & 0.16 & 6.22 & 12.73 & 220.31 \\
\hline & 27.16 & 0.16 & 6.25 & 12.73 & 220.22 \\
\hline & 19.32 & 0.11 & 6.26 & 12.75 & 157.31 \\
\hline \multirow{15}{*}{$\begin{array}{l}200 \mathrm{~W} \\
8 \mathrm{~min}\end{array}$} & 28.63 & 0.17 & 6.15 & 12.71 & 228.11 \\
\hline & 24.08 & 0.13 & 6.22 & 12.75 & 194.82 \\
\hline & 27.43 & 0.17 & 6.27 & 12.73 & 223.30 \\
\hline & 26.00 & 0.16 & 6.29 & 12.73 & 212.05 \\
\hline & 26.17 & 0.15 & 6.16 & 12.73 & 209.15 \\
\hline & 27.51 & 0.17 & 6.29 & 12.71 & 224.21 \\
\hline & 27.35 & 0.17 & 6.26 & 12.73 & 222.26 \\
\hline & 27.39 & 0.16 & 6.25 & 12.74 & 222.31 \\
\hline & 27.42 & 0.17 & 6.25 & 12.73 & 222.35 \\
\hline & 20.51 & 0.12 & 6.27 & 12.75 & 167.33 \\
\hline & 19.70 & 0.11 & 6.21 & 12.75 & 159.07 \\
\hline & 24.86 & 0.15 & 6.27 & 12.71 & 202.21 \\
\hline & 26.27 & 0.15 & 6.21 & 12.73 & 211.69 \\
\hline & 26.51 & 0.16 & 6.22 & 12.73 & 214.10 \\
\hline & 26.84 & 0.16 & 6.24 & 12.73 & 217.23 \\
\hline \multirow{32}{*}{$\begin{array}{l}300 \mathrm{~W} \\
8 \mathrm{~min}\end{array}$} & 26.78 & 0.16 & 6.31 & 12.66 & 218.22 \\
\hline & 27.33 & 0.16 & 6.27 & 12.67 & 221.58 \\
\hline & 28.14 & 0.17 & 6.18 & 12.66 & 224.71 \\
\hline & 21.21 & 0.12 & 6.26 & 12.65 & 171.32 \\
\hline & 27.04 & 0.16 & 6.29 & 12.67 & 219.72 \\
\hline & 27.38 & 0.16 & 6.20 & 12.53 & 216.91 \\
\hline & 28.26 & 0.17 & 6.29 & 12.52 & 226.89 \\
\hline & 28.64 & 0.16 & 6.12 & 12.52 & 223.85 \\
\hline & 26.33 & 0.16 & 6.27 & 12.53 & 211.19 \\
\hline & 30.85 & 0.18 & 6.25 & 12.51 & 245.94 \\
\hline & 24.50 & 0.14 & 6.24 & 12.74 & 198.45 \\
\hline & 26.97 & 0.15 & 6.22 & 12.71 & 217.54 \\
\hline & 22.21 & 0.13 & 6.22 & 12.75 & 179.67 \\
\hline & 26.99 & 0.16 & 6.20 & 12.73 & 217.09 \\
\hline & 26.63 & 0.15 & 6.21 & 12.73 & 214.55 \\
\hline & 26.55 & 0.16 & 6.36 & 12.65 & 217.91 \\
\hline & 25.27 & 0.15 & 6.30 & 12.65 & 205.30 \\
\hline & 28.01 & 0.15 & 6.18 & 12.66 & 223.67 \\
\hline & 21.95 & 0.13 & 6.20 & 12.65 & 175.45 \\
\hline & 25.61 & 0.14 & 6.27 & 12.64 & 207.06 \\
\hline & 21.59 & 0.13 & 6.30 & 12.62 & 175.09 \\
\hline & 28.03 & 0.17 & 6.27 & 12.65 & 226.84 \\
\hline & 28.18 & 0.16 & 6.17 & 12.62 & 223.89 \\
\hline & 28.12 & 0.17 & 6.17 & 12.66 & 224.07 \\
\hline & 28.59 & 0.17 & 6.21 & 12.67 & 229.47 \\
\hline & 29.12 & 0.16 & 6.27 & 12.67 & 236.09 \\
\hline & 29.61 & 0.18 & 6.25 & 12.65 & 238.63 \\
\hline & 29.85 & 0.18 & 6.25 & 12.65 & 240.59 \\
\hline & 24.14 & 0.14 & 6.32 & 12.64 & 196.72 \\
\hline & 28.30 & 0.16 & 6.25 & 12.65 & 228.07 \\
\hline & 27.81 & 0.17 & 6.26 & 12.65 & 224.62 \\
\hline & 28.44 & 0.17 & 6.22 & 12.65 & 228.25 \\
\hline
\end{tabular}




\begin{tabular}{|c|c|c|c|c|c|}
\hline & 27.74 & 0.16 & 6.31 & 12.66 & 226.07 \\
\hline & 28.39 & 0.16 & 6.18 & 12.64 & 226.25 \\
\hline & 23.00 & 0.13 & 6.26 & 12.61 & 185.20 \\
\hline \multirow{15}{*}{$\begin{array}{l}300 \mathrm{~W} \\
2 \mathrm{~min}\end{array}$} & 21.08 & 0.12 & 6.25 & 12.64 & 169.69 \\
\hline & 23.64 & 0.14 & 6.24 & 12.64 & 189.96 \\
\hline & 26.77 & 0.16 & 6.22 & 12.65 & 214.87 \\
\hline & 16.51 & 0.10 & 6.27 & 12.66 & 133.72 \\
\hline & 22.65 & 0.14 & 6.29 & 12.64 & 183.48 \\
\hline & 26.27 & 0.15 & 6.27 & 12.66 & 212.83 \\
\hline & 25.32 & 0.14 & 6.27 & 12.65 & 204.93 \\
\hline & 22.11 & 0.13 & 6.29 & 12.62 & 178.94 \\
\hline & 16.93 & 0.10 & 6.24 & 12.65 & 136.21 \\
\hline & 24.86 & 0.15 & 6.34 & 12.64 & 203.03 \\
\hline & 27.47 & 0.17 & 6.26 & 12.66 & 222.08 \\
\hline & 27.13 & 0.16 & 6.32 & 12.67 & 221.76 \\
\hline & 27.05 & 0.16 & 6.26 & 12.64 & 218.18 \\
\hline & 19.27 & 0.11 & 6.24 & 12.62 & 154.67 \\
\hline & 28.32 & 0.17 & 6.21 & 12.66 & 227.07 \\
\hline \multirow{15}{*}{$\begin{array}{c}300 \mathrm{~W} \\
4 \mathrm{~min}\end{array}$} & 26.89 & 0.16 & 6.17 & 12.66 & 214.32 \\
\hline & 22.25 & 0.12 & 6.08 & 12.65 & 174.59 \\
\hline & 27.62 & 0.17 & 6.25 & 12.65 & 222.62 \\
\hline & 26.13 & 0.15 & 6.20 & 12.65 & 208.92 \\
\hline & 28.47 & 0.16 & 6.22 & 12.66 & 228.70 \\
\hline & 26.64 & 0.16 & 6.32 & 12.66 & 217.54 \\
\hline & 28.52 & 0.16 & 6.30 & 12.65 & 231.69 \\
\hline & 28.58 & 0.16 & 6.17 & 12.66 & 227.79 \\
\hline & 26.92 & 0.15 & 6.16 & 12.64 & 213.64 \\
\hline & 25.51 & 0.15 & 6.20 & 12.65 & 203.89 \\
\hline & 26.21 & 0.15 & 6.30 & 12.65 & 212.96 \\
\hline & 26.85 & 0.15 & 6.29 & 12.65 & 217.68 \\
\hline & 27.09 & 0.16 & 6.32 & 12.64 & 220.76 \\
\hline & 27.62 & 0.17 & 6.30 & 12.66 & 224.62 \\
\hline & 21.45 & 0.13 & 6.27 & 12.62 & 173.18 \\
\hline
\end{tabular}




\section{S2 Contact Angle Measurements}

Surface hydrophilicity is reported to influence interfacial adhesion by influencing wetting properties. Better wetting means better contact between composite and adhesive, which potentially enhances interfacial adhesion.1-3 We measured contact angle using Ramé-Hart Model 250 Contact Angle Goniometer with water as testing liquid, and pictures were acquired ten seconds after contacting water with laminate surfaces. Raw T300 laminates possess hydrophobic surfaces with contact angle as 74 degrees while all plasma treated surfaces possess contact angles as 0 degree (total wetting). We have observed enhanced shear strengths of cured coupons after plasma treatment, but this cannot be correlated to wetting properties since all plasma treated laminates show the same contact angles (i.e., $\sim 0$ degree) of water. These changes must reflect the combined influence of the increases in surface roughness and changes in the chemical properties of the surface (e.g., increased hydrogen bond donors or acceptors, removal of fluorine residues from curing treatment (vide infra)). It should be noted that the contact angles measured here were about ten seconds after testing liquid was dropped. Although the contact angles reported might deviate from the initial contact angles, they still demonstrate that plasma treated samples are more hydrophilic than untreated surfaces.

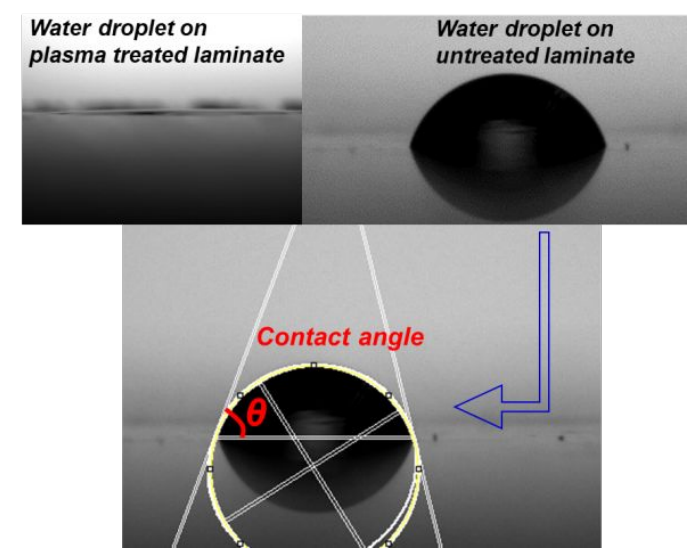

Figure S1. Contact angle pictures by the Ramé-Hart Model 250 Contact Angle Goniometer
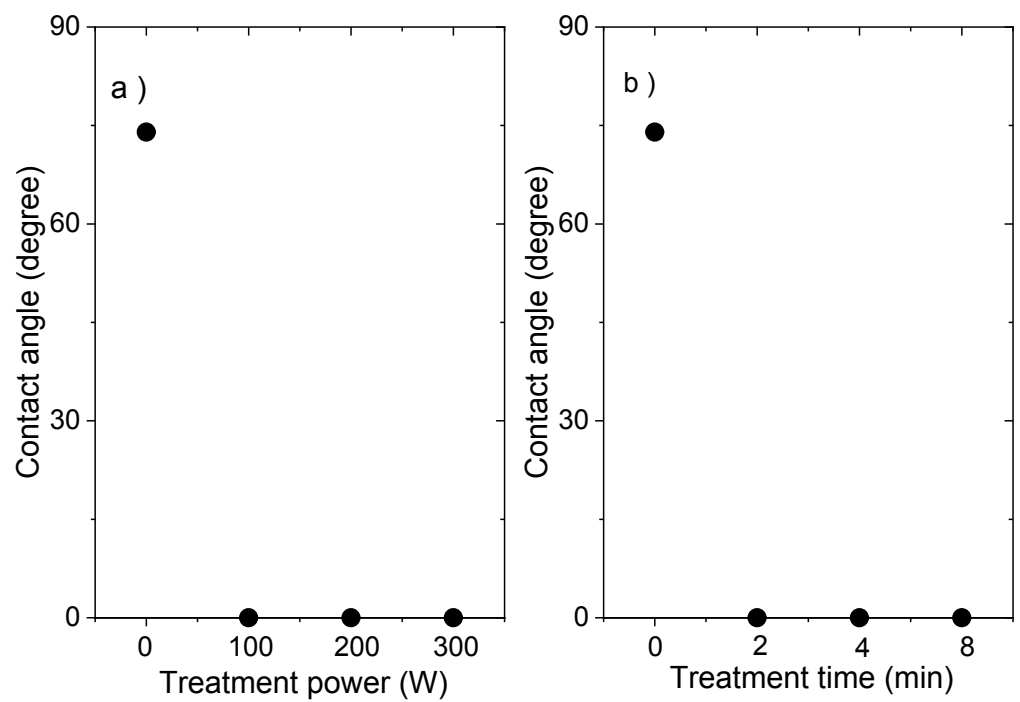

Figure S2. Contact angle of water on plasma treated laminates a) varying plasma treated time with fixed time ( $8 \mathrm{~min})$; b) varying plasma treated time with fixed power $(300 \mathrm{~W})$. Oxygen flow rate $25 \mathrm{~cm}^{3} \mathrm{~min}^{-1}$; Pressure $30 \pm 3 \mathrm{~Pa}$. 


\section{S3 Atomic Force Microscopy to Determine Surface Roughness}

Figure S3 shows representative pictures $(50 \mu \mathrm{m} \times 50 \mu \mathrm{m})$ of raw and plasma treated laminates $(300 \mathrm{~W}, 8 \mathrm{~min}$, oxygen flow rate $25 \mathrm{~cm}^{3} \mathrm{~min}^{-1}$, pressure $30 \pm 3 \mathrm{~Pa}$ ), which correlates to the observation from surface profilometry that more 'valleys' are formed after plasma treatment. Figure $\mathbf{S 4}$ implies surface roughness of laminates increases from $50 \pm 13$ $\mathrm{nm}$ to $107 \pm 29 \mathrm{~nm}$, which further explains the formation of 'valleys' shown in Figure S3.
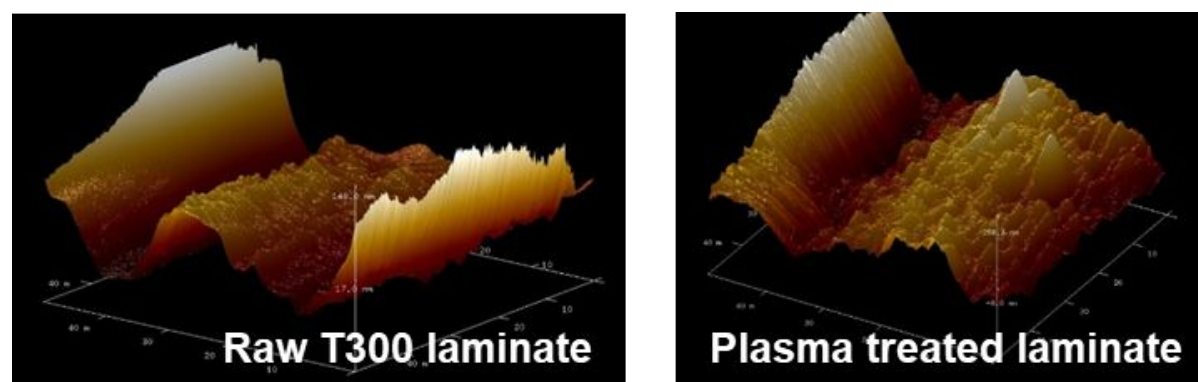

Figure S3. Representative AFM pictures $(50 \mu \mathrm{m} \times 50 \mu \mathrm{m})$ of raw and plasma treated T300 laminates $(300 \mathrm{~W}, 8 \mathrm{~min}$, oxygen flow rate $25 \mathrm{~cm}^{3} \mathrm{~min}^{-1}$, pressure $30 \pm 3 \mathrm{~Pa}$ ).

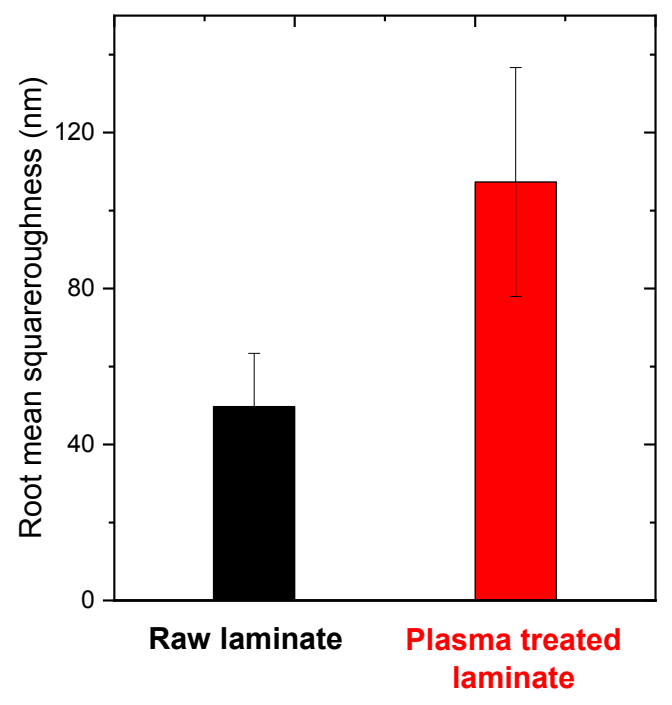

Figure S4. Surface roughness raw $(\square)$ and plasma treated composites $\left(300 \mathrm{~W}, 8 \mathrm{~min}\right.$, oxygen flow rate $25 \mathrm{~cm}^{3} \mathrm{~min}-$ , , pressure $30 \pm 3 \mathrm{~Pa} \square$ ) determined by AFM. 


\section{S4 X-Ray Photoelectron Spectra of Composites}

Table S2. Peaking fitting parameters of O1s spectra

\begin{tabular}{cccccc}
\hline \multirow{2}{*}{ T300 laminates } & \multicolumn{5}{c}{ Percentage of features in C1s spectra (\%) } \\
\cline { 2 - 6 } & $\mathrm{sp}^{2} \mathrm{C}$ & $\mathrm{sp}^{3} \mathrm{C}$ & $\mathrm{C}-\mathrm{O}$ & $\mathrm{O}=\mathrm{C}-\mathrm{O}$ & $-\mathrm{CF}_{\mathrm{x}}$ \\
\hline Untreated laminate & 24 & 40 & 30 & 4 & 2 \\
\hline 100 W 8 min & 61 & 19 & 18 & 2 & 0 \\
\hline $200 \mathrm{~W} 8 \mathrm{~min}$ & 18 & 58 & 21 & 3 & 0 \\
\hline $300 \mathrm{~W} 8 \mathrm{~min}$ & 17 & 58 & 22 & 3 & 0 \\
\hline $300 \mathrm{~W} 2 \mathrm{~min}$ & 69 & 16 & 12 & 3 & 0 \\
\hline $300 \mathrm{~W} 4 \mathrm{~min}$ & 53 & 24 & 14 & 9 & 0 \\
\hline
\end{tabular}

We investigated surface chemistry of laminates by XPS. Figure $\mathbf{S} 5$ shows C1s spectra of untreated and plasma treated laminates. The results here suggest there is no significant increases of carboxylic acids (i.e., $\mathrm{O}=\mathrm{C}-\mathrm{O}$ feature) after plasma treatments except for an outlier ( $300 \mathrm{~W}, 4$ min, oxygen flow rate $25 \mathrm{~cm}^{3} \mathrm{~min}^{-1}$, pressure $\left.30 \pm 3 \mathrm{~Pa}\right)$.
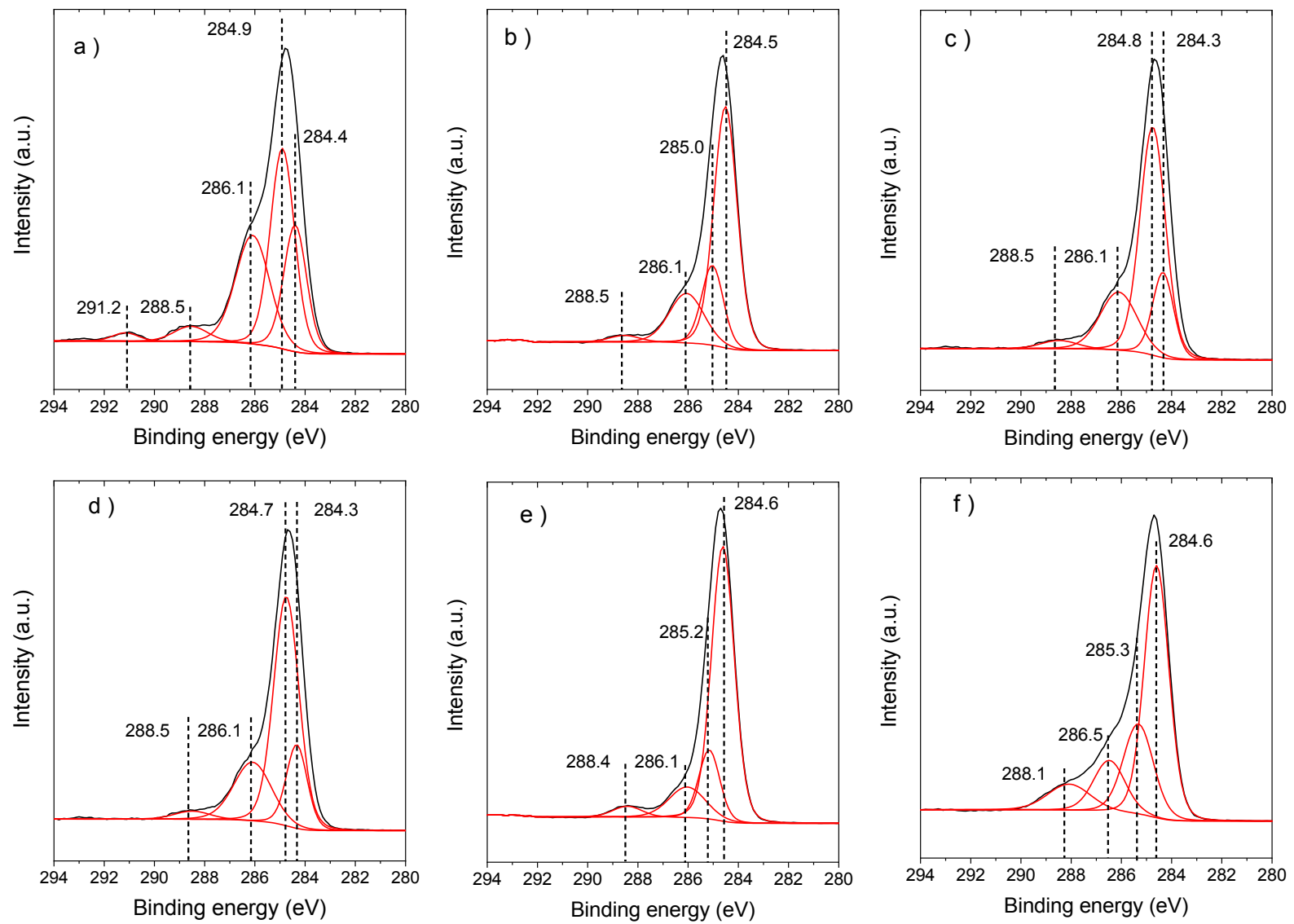

Figure S5. Raw C1s spectra (-) with fit features (-) for a) untreated laminate, b) $100 \mathrm{~W} 8 \mathrm{~min}, \mathrm{c}) 200 \mathrm{~W} 8 \mathrm{~min}, \mathrm{~d}$ ) $300 \mathrm{~W} 8 \mathrm{~min}, \mathrm{e}) 300 \mathrm{~W} 2 \mathrm{~min}, \mathrm{f}) 300 \mathrm{~W} 4 \mathrm{~min}$. The flow rate $\left(25 \mathrm{~cm}^{3} \mathrm{~min}^{-1}\right)$ and pressure $\left(30 \pm 3 \mathrm{~Pa}_{2}\right)$ of oxygen were constant for all treatments. 
We performed peak fitting for O1s spectra (Fig. S6) of all laminates. Except for one plasma treated laminate (300 W, 4 min, oxygen flow rate $25 \mathrm{~cm}^{3} \mathrm{~min}^{-1}$, pressure $30 \pm 3 \mathrm{~Pa}$ ), all other spectra possess a single peak with binding energy from $531.8 \mathrm{eV}$ to $532.0 \mathrm{eV}$, which suggests there is no significant difference among the identities of oxygen functions.

Table S3. Peaking fitting parameters of O1s spectra

\begin{tabular}{|c|c|c|c|c|}
\hline T300 laminates & \multicolumn{4}{|c|}{$\mathrm{O}$ binding energy $(\mathrm{eV})$} \\
\hline Raw laminate & \multicolumn{4}{|c|}{531.9} \\
\hline $100 \mathrm{~W} 8 \mathrm{~min}$ & \multicolumn{4}{|c|}{532.0} \\
\hline $200 \mathrm{~W} 8 \mathrm{~min}$ & \multicolumn{4}{|c|}{532.0} \\
\hline $300 \mathrm{~W} 8 \mathrm{~min}$ & \multicolumn{4}{|c|}{532.0} \\
\hline $300 \mathrm{~W} 2 \mathrm{~min}$ & \multicolumn{4}{|c|}{531.8} \\
\hline \multirow[t]{2}{*}{$300 \mathrm{~W} 4 \mathrm{~min}$} & $\mathrm{O} 1 \%$ & $\begin{array}{c}\text { Binding } \\
\text { energy of } \mathrm{O} 1 \\
(\mathrm{eV})\end{array}$ & $\mathrm{O} 2 \%$ & $\begin{array}{c}\text { Binding energy } \\
\text { of } \mathrm{O} 2(\mathrm{eV})\end{array}$ \\
\hline & 69.1 & 531.9 & 30.9 & 533.5 \\
\hline
\end{tabular}
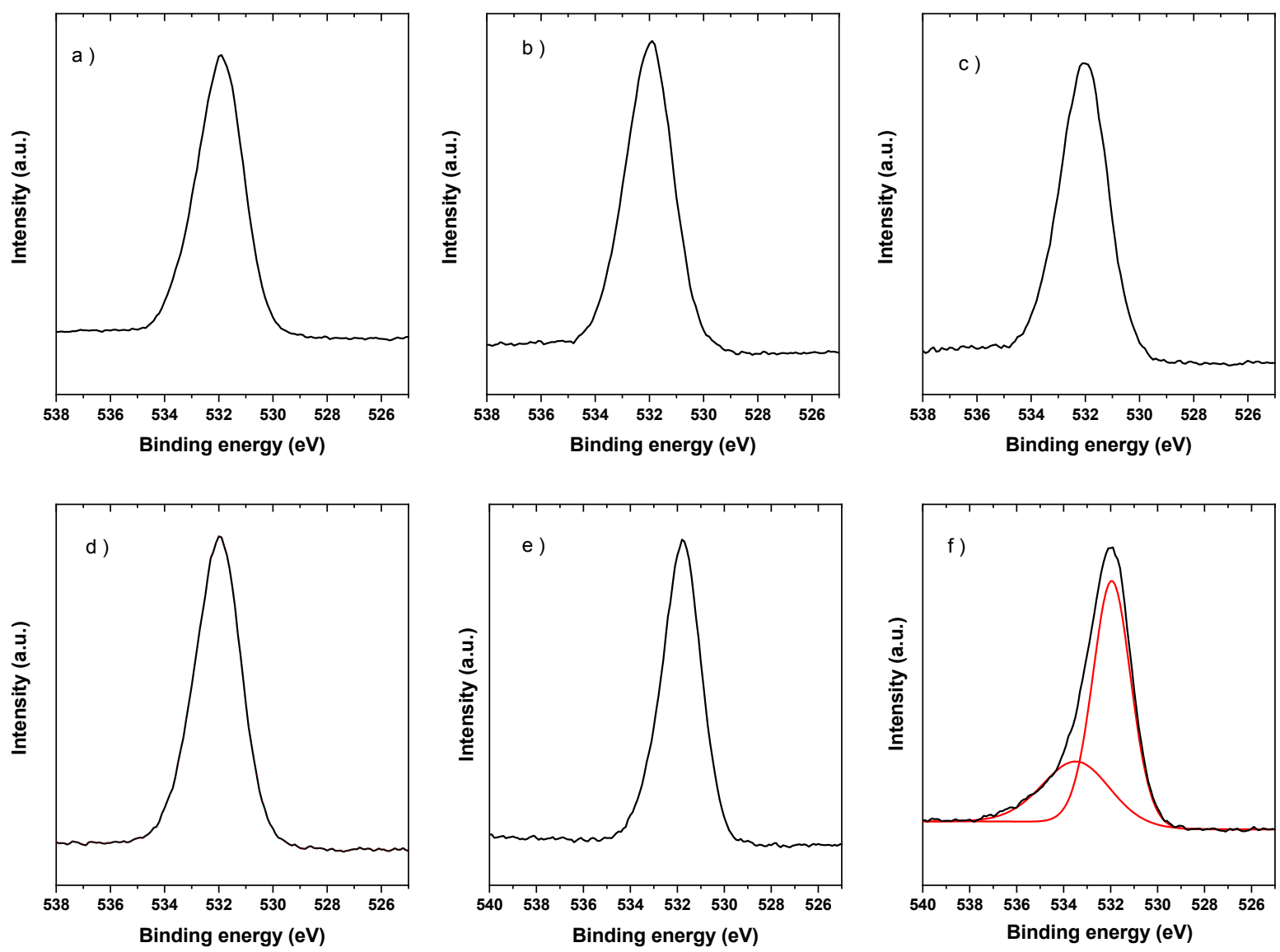

Figure S6. Raw O1s spectra (-) with fit features (-) for a) untreated laminate, b) $100 \mathrm{~W} 8$ min, c) $200 \mathrm{~W} 8 \mathrm{~min}, \mathrm{~d}$ ) $300 \mathrm{~W} 8 \mathrm{~min}, \mathrm{e}) 300 \mathrm{~W} 2 \mathrm{~min}, \mathrm{f}) 300 \mathrm{~W} 4 \mathrm{~min}$. The flow rate $\left(25 \mathrm{~cm}^{3} \mathrm{~min}^{-1}\right)$ and pressure $\left(30 \pm 3 \mathrm{~Pa}_{2}\right)$ of oxygen were constant for all treatments. 
As discussed in the main text, we fit N1s spectra of all laminates into two features: N1 with binding energy from 399.4 $\mathrm{eV}$ to $399.5 \mathrm{eV}$ and $\mathrm{N} 2$ from $400.6 \mathrm{eV}$ to $400.8 \mathrm{eV}$.

Table S4. Peak fitting details of N1s spectra

\begin{tabular}{ccccc}
\hline T300 composites & N1\% & $\begin{array}{c}\text { Binding energy } \\
\text { of N1 (eV) }\end{array}$ & N2\% & $\begin{array}{c}\text { Binding energy of } \\
\text { N2 (eV) }\end{array}$ \\
\hline Raw composite & 90.9 & 399.4 & 9.1 & 400.8 \\
\hline 100 W 8 min & 70.3 & 399.5 & 29.7 & 400.8 \\
\hline 200 W 8 min & 66.7 & 399.5 & 33.4 & 400.8 \\
\hline 300 W 8 min & 61.9 & 399.5 & 38.1 & 400.6 \\
\hline 300 W 2 min & 66.8 & 399.5 & 33.2 & 400.8 \\
\hline 300 W 4 min & 63.3 & 399.5 & 36.7 & 400.8 \\
\hline
\end{tabular}
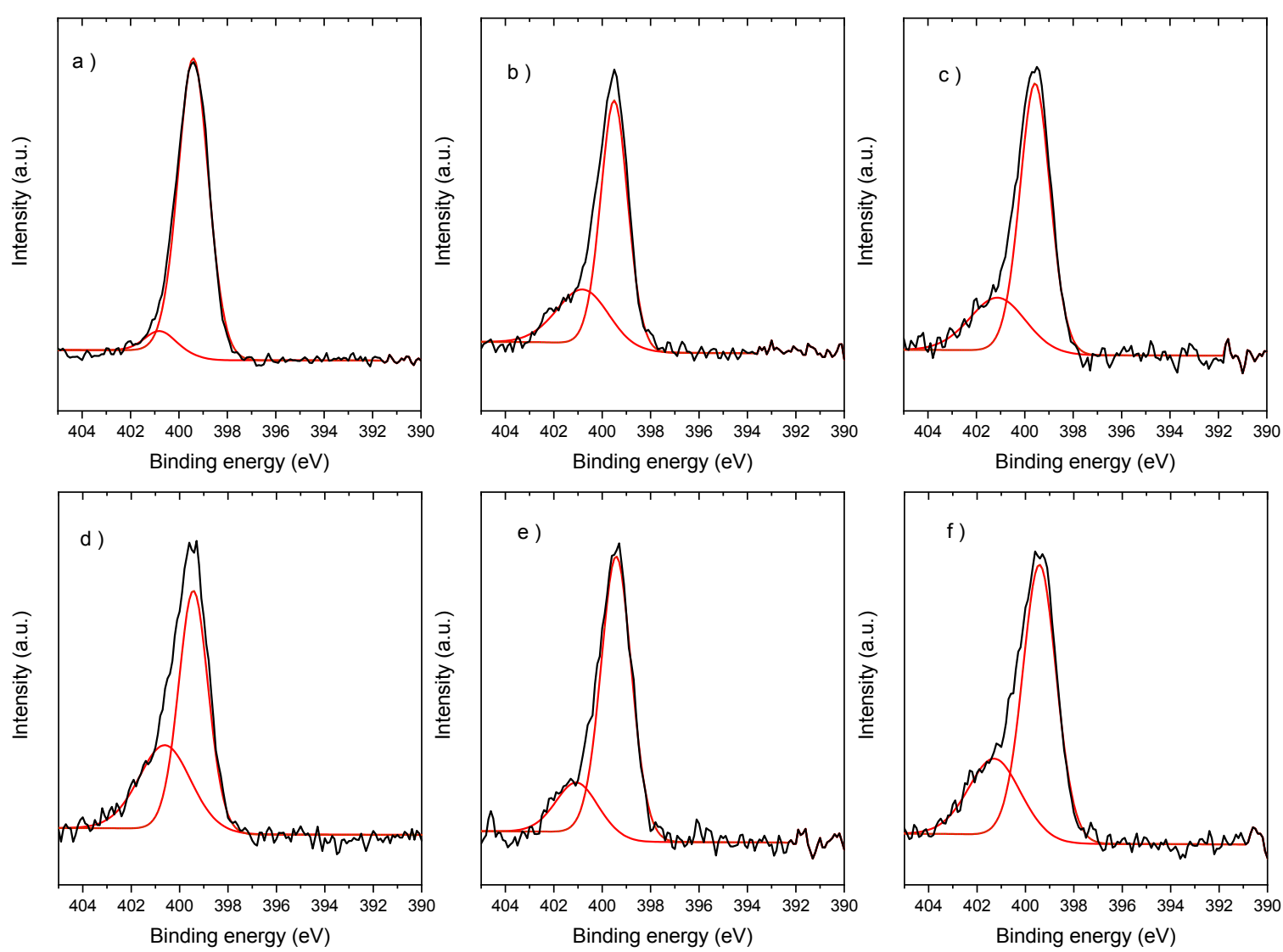

Figure S7. Raw N1s spectra (-) with fit features (-) for a) untreated laminate, b) $100 \mathrm{~W} 8$ min, c) $200 \mathrm{~W} 8 \mathrm{~min}, \mathrm{~d}$ ) $300 \mathrm{~W} 8 \mathrm{~min}, \mathrm{e}) 300 \mathrm{~W} 2 \mathrm{~min}, \mathrm{f}) 300 \mathrm{~W} 4 \mathrm{~min}$. The flow rate $\left(25 \mathrm{~cm}^{3} \mathrm{~min}^{-1}\right)$ and pressure $\left(30 \pm 3 \mathrm{~Pa}_{2}\right)$ of oxygen were constant for all treatments. 


\section{S5 Confocal Fluorescence Microscopy}

As mentioned in this paper, T300 laminates give off strong fluorescence signal and this is confirmed first by The Zeiss Observer Z1 microscope. A mercury lamp is equipped with filter and excitation light wavelength is from $500 \mathrm{~nm}$ to $600 \mathrm{~nm}$. ZEISS Axiocam 503 color camera was used to photograph composite surfaces and Figure S8 shows raw T300 laminate surface under $2.5 \times$ objective. The laminate surfaces show shiny and black areas with significantly different fluorescence intensity, which suggests that there are fluorophores on the surfaces.

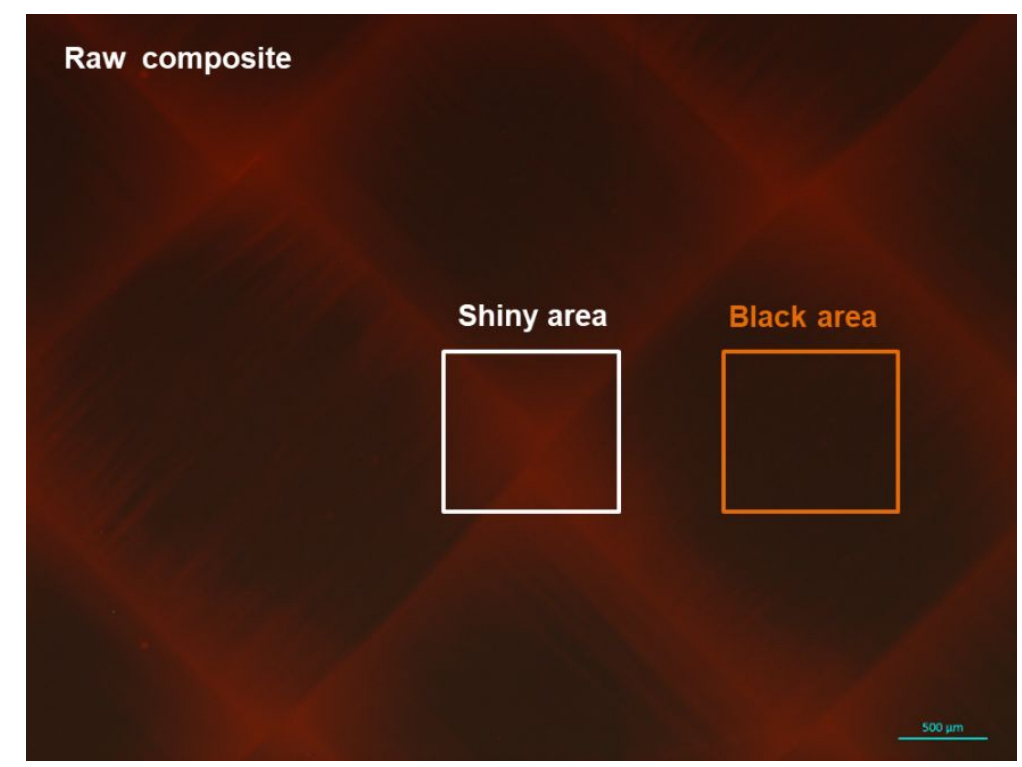

Figure S8. Fluorescence intensity distribution on the surfaces of raw laminates.

To investigate fluorescence intensity, Leica TCS SP8 confocal microscope was used with 561 nm laser for excitation and emission was confined from $600 \mathrm{~nm}$ to $630 \mathrm{~nm}$. Fluorescence intensities are compared between black and shiny areas on raw samples and plotted in Figure S9. Fluorescence intensity of shiny areas on raw composites can be $4 \pm$ 2.6 and this is even comparable to that of fluorescence dye covered surface of plasma treated samples $(4 \pm 3.2)$. Thus, we do not use fluorescence intensities of shiny areas to determine whether Texas Red sulfonyl chloride dye is grafted or not. Instead, fluorescence intensities of black areas are compared in main text and those of shiny areas are summarized in Figure S10. 


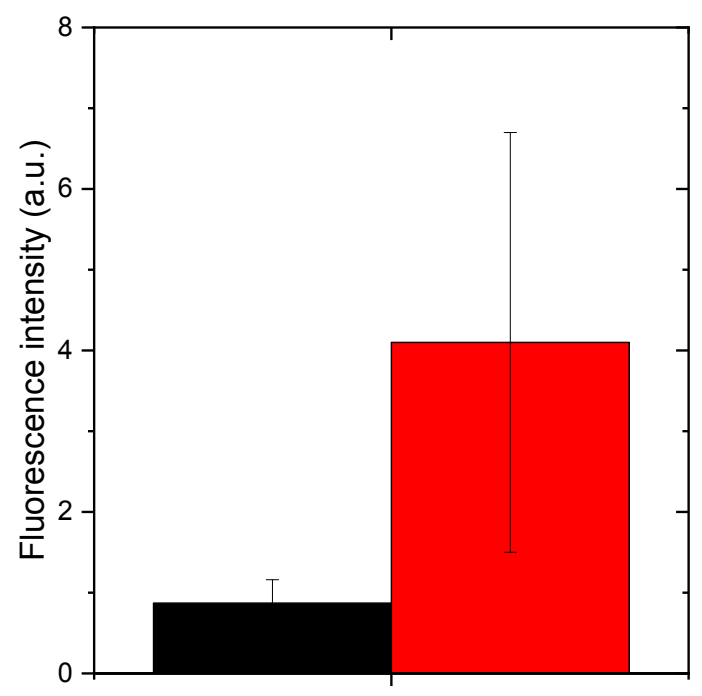

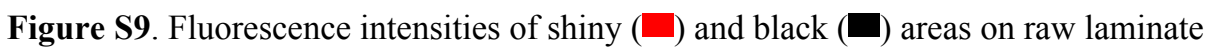
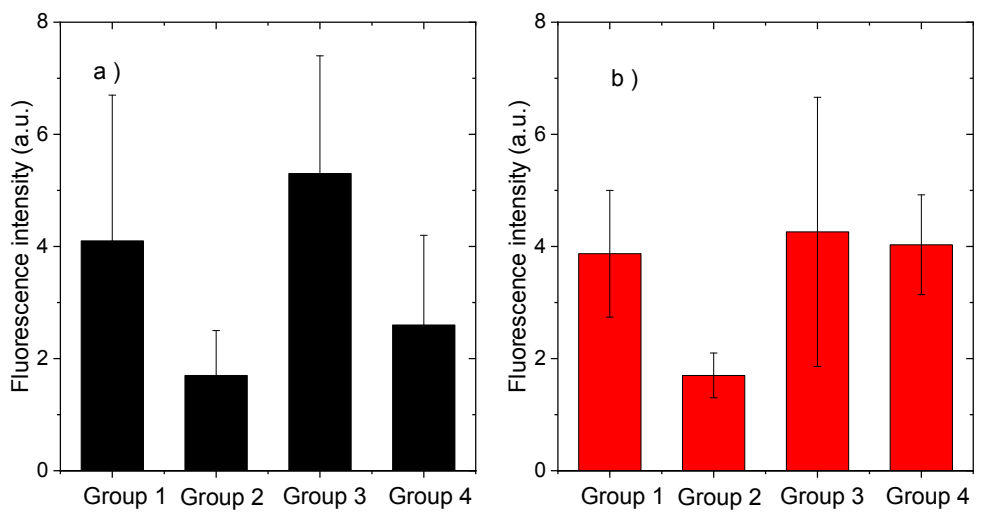

Figure S10. Fluorescence intensity on shiny areas of a) raw $(\mathbf{G})$ and b) plasma treated laminates $(300 \mathrm{~W}, 8 \mathrm{~min}$, oxygen flow rate $25 \mathrm{~cm}^{3} \mathrm{~min}^{-1}$, pressure $\left.30 \pm 3 \mathrm{~Pa}\right)(\square)$; Mean grey value averaged over all pixels, $(512$ pixel $\times 512$ pixel per picture; all intensities averaged on 15-40 pictures). Group 1: laminates cleaned with acetone; Group 2 : laminates first cleaned with acetone and then treated in $\mathrm{H}_{2} \mathrm{SO}_{4}(1 \mathrm{M}, 353 \mathrm{~K}, 24$ hours); Group 3 : laminates of group 1 grafted with Texas Red dye; Group 4 : laminated of group 2 grafted with Texas Red dye. 


\section{S6 Complementary Figures}

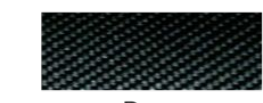

Prepreg

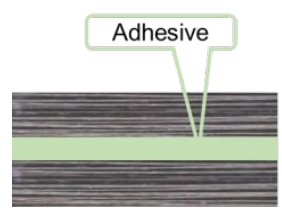

T300 composite
$0.69 \mathrm{MPa}, 450 \mathrm{~K}$

$\Longrightarrow$

Laminate

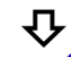

$\mathrm{O}_{2}^{+}$

$0.69 \mathrm{MPa}, 450 \mathrm{~K}$

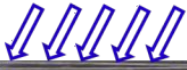

Plasma treatment

Figure S11. The preparation of carbon fiber composite laminates, the subsequent oxygen plasma treatment, and the adhesion and curing process used to create coupons for lap shear tests.

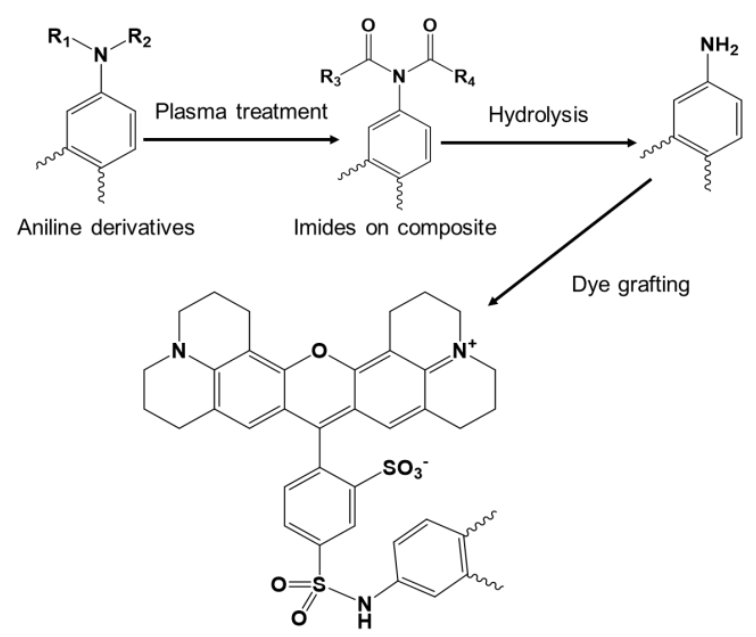

Figure S12. Proposed reaction pathways of aniline derivatives on T300 composites during oxygen plasma treatment, acid treatment and dye grafting

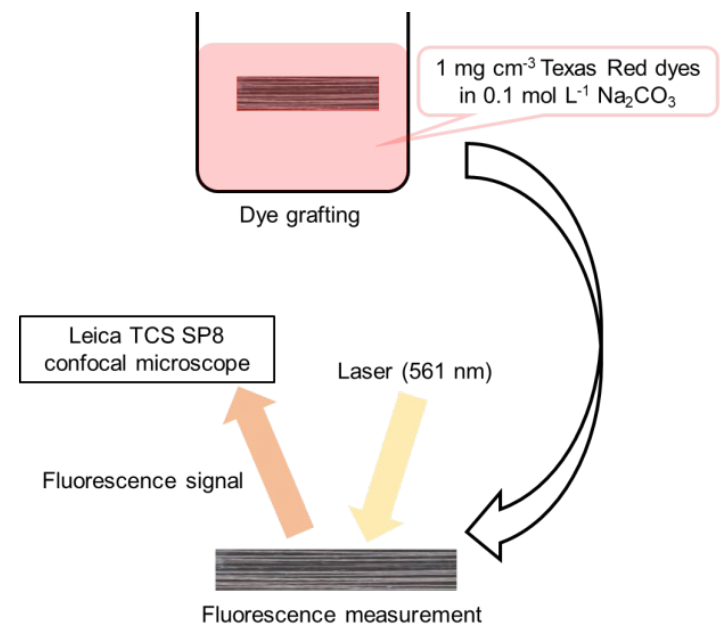


Figure S13. Process for grafting fluorophore onto laminates and measuring fluorescence intensity

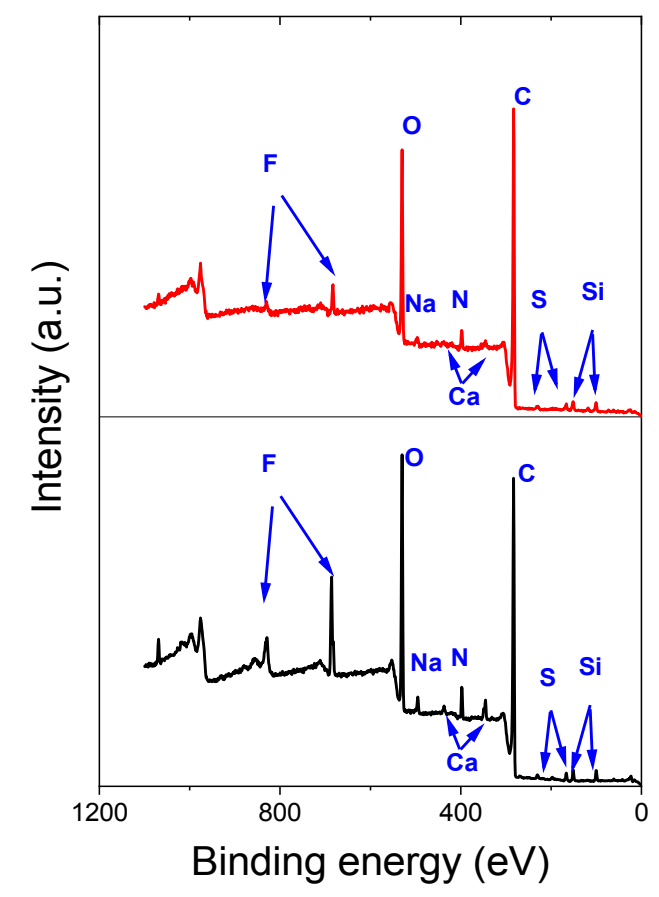

Figure S14. X-ray photoelectron survey scans for untreated (-) and plasma treated (-) laminate surfaces $(300 \mathrm{~W}, 8$ $\min , 25 \mathrm{~cm}^{3} \mathrm{~min}^{-1}, 30 \pm 3 \mathrm{~Pa} \mathrm{O}_{2}$ ).

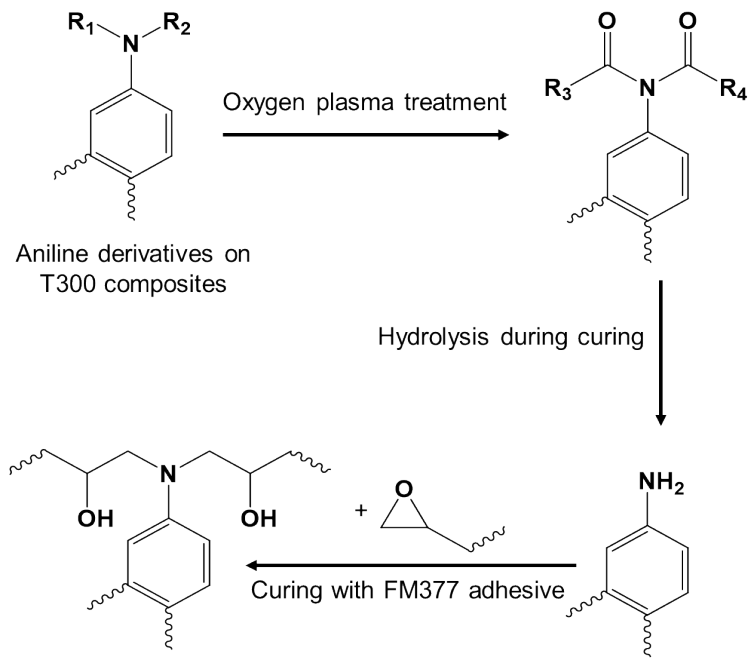

Figure S15. Proposed reaction pathways of aniline derivatives on T300 laminates during oxygen plasma treatment and composite curing. 


\section{References}

1. Zaldivar, R. J.; Kim, H. I.; Steckel, G. L.; Nokes, J. P.; Morgan, B. A., Effect of Processing Parameter Changes on the Adhesion of Plasma-treated Carbon Fiber Reinforced Epoxy Composites. Journal of Composite Materials 2009, 44 (12), 1435-1453.

2. Zaldivar, R. J.; Steckel, G. L.; Morgan, B. A.; Nokes, J. P.; Kim, H. I., Bonding Optimization on Composite Surfaces using Atmospheric Plasma Treatment. Journal of Adhesion Science and Technology 2012, 26 (1-3), 381-401.

3. Zaldivar, R. J.; Steckel, G. L.; Nokes, J. P.; Morgan, B. A.; Kim, H. I., Characterization of atmospheric plasma as a surface preparation process for the bonding of space composite materials. The Journal of Strain Analysis for Engineering Design 2013, 49 (3), 171-178. 